\title{
Thermal, miscibility gap and microstructural studies of organic analog of metal-nonmetal system: p-dibromobenzene-succinonitrile
}

\author{
R.N. Rai ${ }^{\mathrm{a}, *}$, U.S. Rai ${ }^{\mathrm{b}}$, K.B.R. Varma ${ }^{\mathrm{a}}$ \\ ${ }^{a}$ Materials Research Centre, Indian Institute of Science, Bangalore 560 012, India \\ ${ }^{\mathrm{b}}$ Department of Chemistry, Banaras Hindu University, Varanasi 221 005, India
}

Received 25 July 2001; received in revised form 23 October 2001; accepted 25 October 2001

\begin{abstract}
The two immiscible liquid phases in equilibrium with a single liquid phase have been observed during the phase diagram study of an organic analog of a metal-nonmetal system, involving $p$-dibromobenzene-succinonitrile (DBB-SCN). The phase equilibrium shows the formation of a eutectic and a monotectic, with large miscibility gap in the system, contain 0.982 and 0.057 mole fractions of SCN, respectively, and the consolute temperature is $110{ }^{\circ} \mathrm{C}$ above the monotectic horizontal. The heat of mixing, entropy of fusion, roughness parameter, interfacial energy and excess thermodynamic functions were calculated based on enthalpy of fusion data determined via differential scanning calorimeter (DSC) method. The solid-liquid interfacial energy and its effect on morphological change of monotectic structure have been discussed as well as the interfacial energy balance between the solid and two liquids in the monotectic reaction. Whereas the microstructures of monotectic and eutectic show peculiar characteristic features. (C) 2002 Elsevier Science B.V. All rights reserved.
\end{abstract}

Keywords: Phase diagram; Miscibility gap; Thermochemistry; Eutectic; Solid-liquid interfacial energy; Organic monotectic

\section{Introduction}

The repeated and considerable attempts are being made to study the microstructure and phase diagram of miscibility gap (monotectic) system. The solidification behaviours of monotectic are of potential importance both from fundamental point of view and industrial application such as self-lubricating alloys $[1,2]$. Although, metallic systems constitute an interesting area of investigations [3-5], they are not suitable for detailed study due to high transformation temperature and density difference of the components.

\footnotetext{
* Corresponding author.

E-mail address: rnrai@hotmail.com (R.N. Rai).
}

However, low transformation temperature, transparency, wider choice of materials and minimised convection effects are the special features that have prompted a number of research groups $[6,7]$ to work on organic eutectics, monotectics and molecular complexes. To start with organic systems were studied as model system but now-a-days, these are being used in various applications [8-11].

Naturally, the monotectic alloys have less been studied due to several difficulties associated with the miscibility gap systems, while few of the articles $[2,12,13]$ explain various interesting phenomena of monotectic alloys. The role of wetting behaviour, interfacial energy, thermal conductivity and buoyancy in a phase separation process has been the subject of 
great discussion. The $p$-dibromobenzene (DBB) is a material of high entropy of fusion, simulates the nonmetallic solidification whereas succinonitrile $(\mathrm{SCN})$ is a material of low entropy of fusion, simulates the metallic solidification. Therefore, the present DBBSCN system, we might say an organic analog of metal-nonmetal systems like $\mathrm{Al}-\mathrm{Si}$ and $\mathrm{Zn}-\mathrm{Bi}$. In this paper, the details concerning phase diagram, thermochemistry, interfacial energy and microstructure of DBB-SCN system are discussed.

\section{Experimental}

\subsection{Materials and purification}

SCN obtained from Aldrich, Germany was purified by repeated distillation under reduced pressure while as received $p$-DBB (Aldrich, Germany) was used. The melting temperatures of DBB and SCN were found to be 87.5 and $56.5^{\circ} \mathrm{C}$ whereas it has been reported in literature [14] to be 87.3 and $57.0{ }^{\circ} \mathrm{C}$, respectively.

\subsection{Phase diagram}

The phase diagram of DBB-SCN system was established in the form of temperature-composition curve. In this method [15], mixtures of two components, under study, covering the entire range of compositions were prepared and these mixtures were homogenised by repeating the process of melting followed by chilling in ice cooled water $4-5$ times. The melting points of complete miscible compositions and the miscibility temperatures of compositions showing immiscibility were determined using a melting point apparatus attached with a precision thermometer associated with an accuracy of $\pm 0.5{ }^{\circ} \mathrm{C}$.

\subsection{Enthalpy of fusion}

The heat of fusion of pure components, eutectic and monotectic were determined [16] via differential scanning calorimeter (TA Instruments DSC-2010). Indium sample was used to calibrate the system, and amount of test sample and heating rate were about $7 \mathrm{mg}$ and $5{ }^{\circ} \mathrm{C} \mathrm{min}^{-1}$, respectively, for each estimation. The values of enthalpy of fusion are reproducible within $\pm 1.0 \%$.

\subsection{Microstructure}

Microstructures of pure components, eutectic and monotectic were recorded [17] by placing a drop of molten compound on a hot glass slide. To cover the melt, a cover slip was glided over the melt and it was allowed to cool to get a super cooled liquid. The melt was nucleated with a seed crystal of the same composition and care was taken to have unidirectional freezing. The slide with the solid was then placed on the platform of optical (Olyempus) microscope. Different regions were viewed with suitable magnifications and photographed.

\section{Results and discussions}

\subsection{Phase diagram}

The phase diagram of DBB-SCN system shows the formation of a monotectic and a eutectic as depicted in Fig. 1, and the numerical values of melting/miscibility temperature corresponding to different compositions are given in Table 1. After a short range of compositions, the two liquids are mutually immiscibile

Table 1

Numerical values of solid-liquid equilibrium and liquid-liquid equilibrium temperature corresponding to different compositions

\begin{tabular}{lc}
\hline Mole fraction of SCN & $\begin{array}{l}\text { Melting/miscibility } \\
\text { of temperature }\left({ }^{\circ} \mathrm{C}\right)\end{array}$ \\
\hline 0.0000 & 87.5 \\
0.0429 & 86.0 \\
0.0567 & 85.0 \\
0.0835 & 107.0 \\
0.1344 & 142.5 \\
0.2466 & 176.0 \\
0.3420 & 190.0 \\
0.4241 & 193.0 \\
0.4954 & 195.0 \\
0.5580 & 192.0 \\
0.6626 & 185.0 \\
0.7466 & 172.0 \\
0.8154 & 149.0 \\
0.8730 & 118.0 \\
0.9217 & 84.0 \\
0.9635 & 60.5 \\
0.9824 & 52.5 \\
0.9900 & 54.0 \\
1.0000 & 56.5 \\
\hline
\end{tabular}




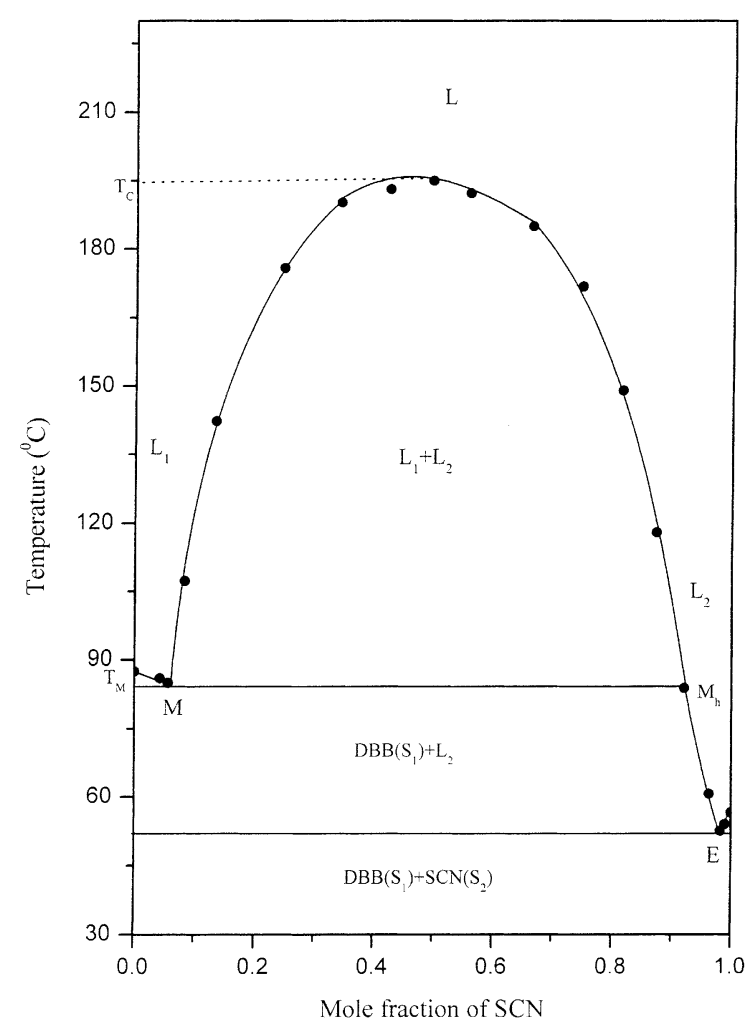

Fig. 1. Phase diagram of $p$-DBB-SCN system: (O) melting/ miscibility temperature.

$\left(\mathrm{L}_{1}+\mathrm{L}_{2}\right)$ and the upper consolute/critical temperature $\left(T_{\mathrm{c}}\right)$ is $110{ }^{\circ} \mathrm{C}$ above the monotectic horizontal. Both the components are miscible in all proportions above the critical temperature. The thermal study of different compositions reveals that there are three reactions of interest, which occur isothermally on solidification. The first reaction concerns the phase separation in two liquids as the liquid of single phase is cooled below the critical temperature $\left(T_{\mathrm{c}}\right)$, and can be written as:

$\mathrm{L} \rightarrow \mathrm{L}_{1}+\mathrm{L}_{2}$

The direct observation of kinetics of phase separation from liquid $\mathrm{L}$ to $\mathrm{L}_{1}+\mathrm{L}_{2}$ is interesting but the mechanism appears to be complicated. It was seen just about separation that there was a disturbance in the whole liquid as a consequence of diffusion, collision between droplets, convection and movement by buoyancy driven fluid flow. A small decrease in potential energy temperature from the critical solution temperature is quite enough for the phase separation process to occur within a few seconds. Although, the exact reason for the existence of miscibility gap is not clear, for the metallic systems the numbers of possibilities have been explained [18] such as compound formation tendencies, atomic radii difference, the valences differences of the component association, etc., any of these might be responsible for the occurrence of miscibility gap in the liquid state. The density difference of the components might be a reason for the phase separation but the systems studied by author, e.g. SCN-DP [19] where the density difference of the components is 0.007 . On the other hand, the density difference in the system SCN-DCB [20] and the system being discussed, SCN-DBB, are 0.256 and 1.276 , respectively, while all these systems showing the miscibility gap are organic analog of metal-nonmetal system. Therefore, the concepts of thermodynamic properties of liquid alloys, such as low viscosity and change in interfacial energy of two liquids corresponding to critical temperature, might be applicable for the phase separation process.

The second reaction, known as monotectic reaction, is formally similar to the eutectic reaction except that one of the product phases is a second liquid phase, $\mathrm{L}_{2}$, as follows:

$\mathrm{L}_{1} \rightarrow \mathrm{S}_{1}+\mathrm{L}_{2}$

The third reaction is the eutectic reaction in which the liquid $\mathrm{L}_{2}$ decompose to give two solids as:

$\mathrm{L}_{2} \rightarrow \mathrm{S}_{1}+\mathrm{S}_{2}$

The monotectic, eutectic and critical solution temperatures in the present case are 85.0, 52.5 and $195.0{ }^{\circ} \mathrm{C}$, respectively.

\section{Thermochemistry}

\subsection{Enthalpy of fusion}

Enthalpy of fusion values of the pure components, the eutectic and the monotectic were determined by the DSC method, and reported in Table 2. For comparison, the value of enthalpy of fusion of eutectic calculated by the mixture law [21] is also included in the same Table. As such, three types of structures are suggested [22]; quasi-eutectic for $\Delta H_{\text {mix }}>0$, 
Table 2

Heat of fusion, entropy of fusion and roughness parameter

\begin{tabular}{lclc}
\hline Materials & Heat of fusion $\left(\mathrm{kJ} \mathrm{mol}^{-1}\right)$ & Entropy of fusion $\left(\mathrm{J} \mathrm{mol}^{-1} \mathrm{~K}^{-1}\right)$ & Roughness parameter $(\alpha)$ \\
\hline DBB & 19.0 & 80.4 & 9.7 \\
SCN & 3.7 & 11.2 & 1.4 \\
DBB-SCN monotectic (experimental) & 17.0 & 47.4 & 5.7 \\
DBB-SCN monotectic (calculated) & 18.0 & & 1.3 \\
DBB-SCN eutectic (experimental) & 3.6 & 11.1 & \\
DBB-SCN eutectic (calculated) & 4.0 & &
\end{tabular}

clustering of molecules for $\Delta H_{\text {mix }}<0$ and molecular solution for $\Delta H_{\text {mix }}=0$. The negative value of $\Delta H_{\text {mix }}$ for the eutectic $\left(-0.4 \mathrm{~kJ} \mathrm{~mol}^{-1}\right)$ suggests clustering of molecules in the binary melt. The entropy of fusion $\left(\Delta S_{\text {fus }}\right)$ values, for different materials have been calculated by dividing the enthalpy of fusion by their corresponding absolute melting temperatures (Table 2). The positive values suggest that the entropy factor favours the melting process. The entropy of fusion of eutectic is lower than that of either of the components. This suggests that the entropy factor is less effective in the melt of the eutectic and almost similar to that of pure SCN.

\subsection{Size of critical nucleus and interfacial energy}

When liquid is cooled below its melting temperature, it does not solidify spontaneously because, under equilibrium condition, the melt contains number of clusters of molecules of different sizes. As long as the clusters are all below the critical size [23], they cannot grow to form crystals and, therefore, no solid would result. The critical size $\left(r^{*}\right)$ of nucleus is related to interfacial energy $(\sigma)$ by the following equation:

$r^{*}=\frac{2 \sigma T_{\text {fus }}}{\Delta H_{\text {fus }} \Delta T}$

where $T_{\text {fus }}, \Delta H_{\text {fus }}$ and $\Delta T$ are melting temperature, heat of fusion, and degree of undercooling, respectively. An estimate of the interfacial energy is given by the expression:

$\sigma=\frac{C \Delta H_{\text {fus }}}{\left(N_{\mathrm{A}}\right)^{1 / 3}\left(V_{\mathrm{m}}\right)^{2 / 3}}$

where $N_{\mathrm{A}}$ is the Avogadro number, $V_{\mathrm{m}}$ the molar volume, and parameter $C$ lies between 0.30 and 0.35 . The calculated values of interfacial energy for different materials are reported in Table 3.

\subsection{Excess thermodynamic functions}

The deviation from the ideal behaviour can best be expressed in terms of excess thermodynamic functions, namely, excess free energy $\left(g^{\mathrm{E}}\right)$, excess enthalpy $\left(h^{\mathrm{E}}\right)$, and excess entropy $\left(s^{\mathrm{E}}\right)$ which give a more quantitative idea about the nature of molecular interactions. The excess thermodynamic functions could be calculated $[20,24,25]$ by using the following equations and the values are given in Table 4:

$$
\begin{aligned}
& g^{\mathrm{E}}=R T\left[x_{1} \ln \gamma_{1}^{1}+x_{2} \ln \gamma_{2}^{1}\right] \\
& h^{\mathrm{E}}=-R T^{2}\left[x_{1} \frac{\partial \ln \gamma_{1}^{1}}{\partial T}+x_{2} \frac{\partial \ln \gamma_{2}^{1}}{\partial T}\right] \\
& s^{\mathrm{E}}=-R\left[x_{1} \ln \gamma_{1}^{1}+x_{2} \ln \gamma_{2}^{1}+x_{1} T \frac{\partial \ln \gamma_{1}^{1}}{\partial T}+x_{2} T \frac{\partial \ln \gamma_{2}^{1}}{\partial T}\right]
\end{aligned}
$$

It is evident from Eqs. (3)-(5) that activity coefficient and its variation with temperature are required to

Table 3

Interfacial energy of $p$-DBB, SCN and their eutectic and monotectic

\begin{tabular}{lc}
\hline Parameter & Interfacial energy $\left(\mathrm{mN} \mathrm{m}^{-1}\right)$ \\
\hline$\sigma_{\mathrm{SL}_{2}}(\mathrm{SCN})$ & 9.6 \\
$\sigma_{\mathrm{SL}_{1}}(\mathrm{DBB})$ & 42.0 \\
$\sigma_{\mathrm{L}_{1} \mathrm{~L}_{2}}(\mathrm{DBB}-\mathrm{SCN})$ & 11.4 \\
$\sigma^{\mathrm{E}}(\mathrm{DBB}-\mathrm{SCN})$ & 10.3 \\
\hline
\end{tabular}

Table 4

Excess thermodynamic functions for the eutectic

\begin{tabular}{llll}
\hline Material & $g^{\mathrm{E}}\left(\mathrm{kJ} \mathrm{mol}^{-1}\right)$ & $h^{\mathrm{E}}\left(\mathrm{kJ} \mathrm{mol}^{-1}\right)$ & $s^{\mathrm{E}}\left(\mathrm{J} \mathrm{mol}^{-1} \mathrm{~K}^{-1}\right)$ \\
\hline $\begin{array}{l}\text { DBB-SCN } \\
\text { eutectic }\end{array}$ & 0.16 & 2.92 & 8.48 \\
\hline
\end{tabular}


calculate the excess functions. Activity coefficient $\left(\gamma^{1}\right)$ could be evaluated $[24,26]$ by using the following equation:

$-\ln \left(x_{i}^{1} \gamma_{i}^{1}\right)=\frac{\Delta H_{\text {fus }, i}}{R}\left(\frac{1}{T_{\text {fus }}}-\frac{1}{T_{i}}\right)$

where $x_{i}^{1}, \Delta H_{\text {fus }, i}, T_{i}$ and $T_{\text {fus }}$ are mole fraction, enthalpy of fusion, melting temperature of component $i$ and $T_{\text {fus }}$ is the eutectic temperature, respectively. The variation of activity coefficient with temperature could be calculated by differentiating Eq. (6) with respect to temperature as follows:

$\frac{\partial \ln \gamma_{i}^{1}}{\partial T}=\frac{\Delta H_{\text {fus }, i}}{R T^{2}}-\frac{\partial x_{i}}{x_{i} \partial T}$

$\partial x_{i} / \partial T$ in this expression can be evaluated by taking two points near the eutectic point. The positive values of excess free energy indicate that there is an associative interaction between like molecules [25,27].

\subsection{Microstructure}

It is well known that in polyphase materials the microstructure gives information about shape and size of the crystallites, which play a very significant role in deciding about mechanical, electrical, magnetic and optical properties of materials. The growth morphology $[28,29]$ of a eutectic system is controlled by the growth characteristics of the constituent phases. According to Hunt and Jackson [30], the type of growth from melts depends upon the interface roughness $(\alpha)$ defined by the following equation:

$\alpha=\xi \frac{\Delta H_{\text {fus }}}{R T}$

where $\xi$ is a crystallographic factor which is generally equal to or less than one. The values of $\alpha$ are reported in Table 2. If $\alpha>2$, the interface is quite smooth and the crystal develops with a faceted morphology. On the other hand, if $\alpha<2$, the interface is rough and many sites are continuously available and the crystal develops with a nonfaceted morphology.

\subsubsection{The microstructure and growth of monotectic}

In monotectic solidification when a liquid of monotectic composition (Fig. 1) is allowed to cool below the monotectic temperature $\left(T_{\mathrm{m}}\right)$, the stability of two liquid phases, $\mathrm{L}_{1}, \mathrm{~L}_{2}$, and a solid phase, $\mathrm{S}$, at the

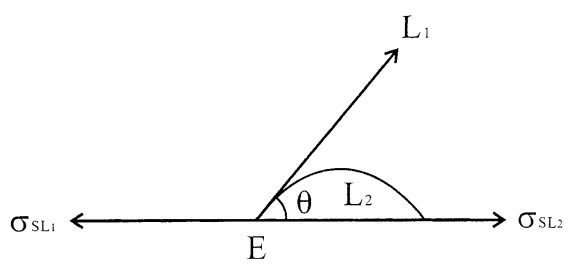

S

Fig. 2. Schematic representation of three phase contact between the solid $\mathrm{S}$, liquid $\mathrm{L}_{1}$ and liquid $\mathrm{L}_{2}$.

solid-liquid interface are required. The necessary conditions for the stable three phases in contact have been explained by Chadwick [28], and the schematic diagram has been presented in Fig. 2. Whether droplets nucleate in the melt or on the solid-liquid interface, depends on the relative magnitude of the three interfacial energies. The requirement for the balance of interfacial energies gives the following conditions:

$\sigma_{\mathrm{SL}_{2}} \leq \sigma_{\mathrm{SL}_{1}}+\sigma_{\mathrm{L}_{1} \mathrm{~L}_{2}}$

and

$\sigma_{\mathrm{SL}_{2}} \geq \sigma_{\mathrm{SL}_{1}}+\sigma_{\mathrm{L}_{1} \mathrm{~L}_{2}}$

where $\sigma_{\mathrm{SL}_{1}}, \sigma_{\mathrm{SL}_{2}}$ and $\sigma_{\mathrm{L}_{1} \mathrm{~L}_{2}}$ are the interfacial energies of solid (S) and the liquid $\mathrm{L}_{1}$, solid (S) and the liquid $\mathrm{L}_{2}$, and liquid $\mathrm{L}_{1}$ and liquid $\mathrm{L}_{2}$, respectively. The surface energies were calculated by using the equation reported earlier [31], and have been tabulated in Table 3. The Cahn wetting condition [32] could be successfully applied to the present system as the interfacial energies are related by the following equation:

$\sigma_{\mathrm{SL}_{2}}<\sigma_{\mathrm{SL}_{1}}+\sigma_{\mathrm{L}_{1} \mathrm{~L}_{2}}$

indicating that the DBB-SCN liquid $\left(\mathrm{L}_{1}\right)$ wets the solidified DBB perfectly. The directionally solidified optical microphotograph of monotectic Fig. 3(a) shows solid lamella associated with few liquid droplets that have solidified later. From the closer view of the lamellas, the existence of discontinuity can be seen at the interface of lamella. From the microstructure, it is evident that the volume fraction of solid phase is much higher than the liquid phase.

\subsubsection{Microstructure of the eutectic}

The eutectic has solidified with dendritic morphology (Fig. 3(b)) and dendrites have grown in a particular 

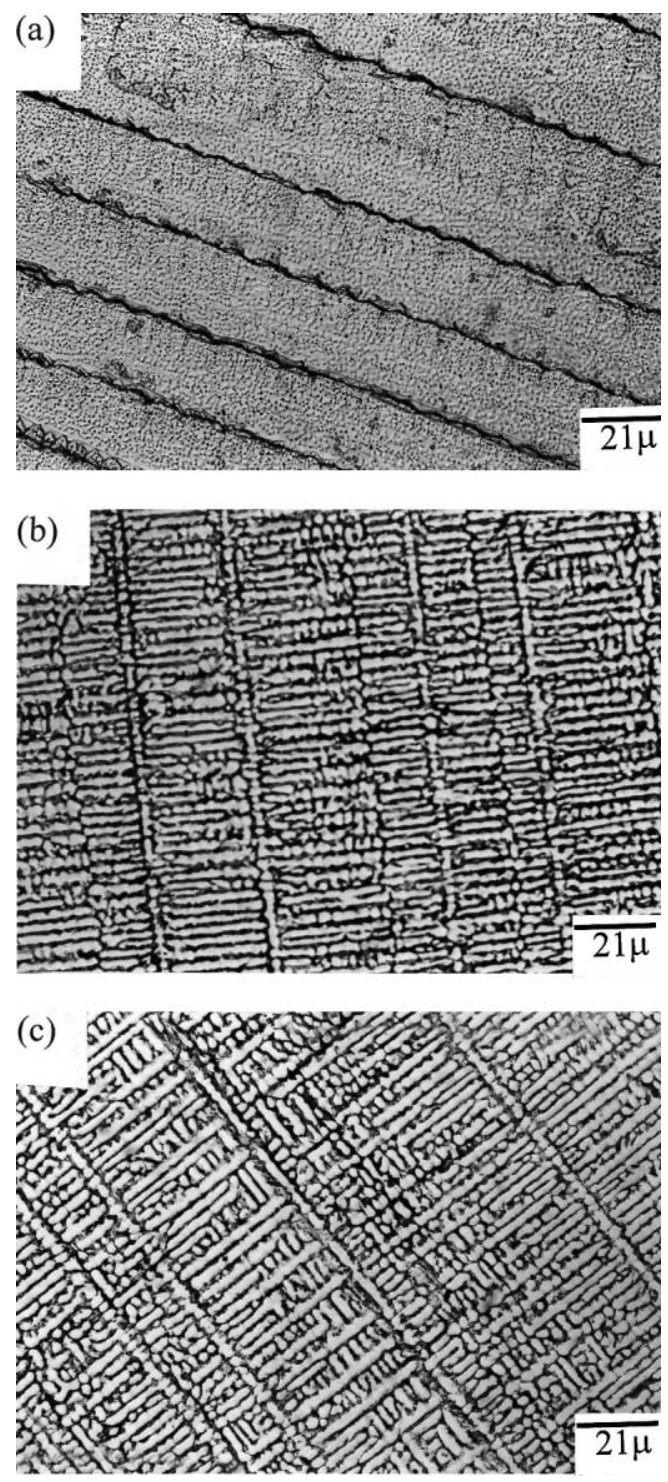

Fig. 3. Optical microphotograph of directionally solidify (a) monotectic, (b) and (c) eutectic.

direction. The primary arms as well as secondary arms have grown parallel to each other. The primary arms are not continuous in nature and in some places have got fragmented in between. The tertiary arms are also being observed in some places. While in Fig. 3(c), primary, secondary and tertiary arms are clearly observed. In this microstructure, the interaction between different dendrite arms can be seen as in some places growth of the primary arm has been stopped by the secondary arm as well as in some other places secondary arm by the tertiary arm. The irregular appearance of secondary and tertiary arms is due to the inhomogeneity in heat distribution during the solidification process.

\section{Acknowledgements}

One of the authors, Dr. R.N. Rai, would like to thank the Indian Institute of Science, Bangalore, for the Research Associateship.

\section{References}

[1] R.N. Gruggel, A. Hellawel, Met. Trans. A 12 (A) (1981) 669.

[2] D.M. Herlach, R.F. Cochrane, I. Egry, H.J. Fecht, A.L. Greer, Int. Mater. Rev. 38 (1993) 273.

[3] R. Trivedi, W. Kurz, Int. Mater. Rev. 32 (1994) 49.

[4] B. Majumdar, K. Chattopadhyay, Met. Trans. A 27 (A) (1996) 2053.

[5] M.E. Glicksman, N.B. Singh, M. Chopra, Manuf. Space 11 (1982) 267.

[6] K. Pigon, A. Krajewska, Thermochim. Acta 58 (1982) 58.

[7] R.P. Rastogi, N.B. Singh, K.D. Dwivedi, Br. Bunsen Ges., Phys. Chem. 85 (1981) 85.

[8] J.P. Farges, Organic Conductors, Marcel Dekker, NY, 1994.

[9] T. Ishiguro, K. Yamaji, Organic Superconductors, Springer, Berlin, 1990.

[10] P. Gunter, Nonlinear Optical Effects and Materials, Springer, Berlin, 2000.

[11] N.B. Singh, T. Henningsen, R.H. Hopkins, R. Mazelsky, R.D. Hamacher, E.P. Supertzi, F.K. Hopkins, D.E. Zelmon, O.P. Singh, J. Cryst. Growth 128 (1993) 976.

[12] B. Derby, J.J. Favier, Acta Met. 7 (1983) 1123.

[13] A. Ecker, D.O. Frazier, J.I.D. Alexander, Met. Trans. 20A (1989) 2517.

[14] S. Budawari, Merck Index, 12th Edition, Merck \& Co., NJ, USA, 1997.

[15] U.S. Rai, K.D. Mandal, Mol. Cryst. Liquid Cryst. 182 (1990) 387.

[16] J.W. Dodd, K.H. Tonge, Thermal methods, in: B.R. Currel (Ed.), Analytical Chemistry by Open Learning, Willey, NY, 1987, p. 120.

[17] R.P. Rastogi, V.K. Rastogi, J. Cryst. Growth 5 (1969) 345.

[18] B. Predel, J. Phase Equilib. 18 (4) (1997) 327.

[19] U.S. Rai, R.N. Rai, Thermochim. Acta 277 (1996) 209.

[20] R.N. Rai, U.S. Rai, Thermochim. Acta 363 (2000) 23.

[21] U.S. Rai, R.N. Rai, J. Cryst. Growth 191 (1998) 234.

[22] N. Singh, B. Singh, U.S. Rai, O.P. Singh, Thermochim. Acta 95 (1985) 291. 
[23] J.W. Christian, The Theory of Phase Transformation in Metals and Alloys, Pergamon Press, Oxford, 1965.

[24] U.S. Rai, O.P. Singh, N.P. Singh, N.B. Singh, Thermochim. Acta 71 (1983) 373.

[25] U.S. Rai, R.N. Rai, Chem. Mater. 11 (11) (1999) 3035.

[26] U.S. Rai, R.N. Rai, J. Therm. Anal. 53 (1998) 883.

[27] J. Wisnaik, A. Tamir, Mixing and Excess Thermodynamic Properties, Elsevier, Amsterdam, 1978.
[28] G.A. Chadwick, Metallography of Phase Transformations, Butterworths, London, 1972.

[29] V.V. Podolinsky, N.Y. Taran, V.G. Drykin, J. Cryst. Growth 96 (1989) 445.

[30] J.D. Hunt, K.A. Jackson, Trans. Met. Soc. AIME 236 (1966) 843.

[31] U.S. Rai, R.N. Rai, J. Cryst. Growth 169 (1996) 563.

[32] J.W. Cahn, J. Chem. Phys. 66 (1977) 3667. 